\title{
Closing Comments: Navigating New Literacies Pedagogies and Practices in Schools
}

\author{
THERESA ROGERS \\ University of British Columbia \\ KATHY SANFORD \\ University of Victoria
}

One of the guiding assumptions of the SSHRC-Funded New Literacies Workshop we hosted in 2011, and from which these papers emanate, is that new literacy practices include an understanding of interactive technologies as part of the new media landscape, providing increased opportunities for learners to develop the competencies to participate in contemporary global cultures (e.g., Jenkins, Clinton, Purushotma, Robison, \& Weigel 2006). Yet with these opportunities come new challenges for teachers and students tantamount to a renegotiation of the curricula at all levels.

This collection complements the resulting volume, Youth Literacies in New Times: Everywhere Everyday (Sanford, Rogers \& Kendrick, in press) that addresses the sophisticated and diverse out-of-school literacies practices youth are engaging in, and the ways they often interrupt the values of traditional, linear thinking and approaches to teaching and learning. As we read through this collection of fascinating accounts of teachers and students as they grapple with this new reality of the digital age and the youth they serve, the complexities, affordances and tensions that accompany these new tools, genres, modes and forms of participation into the schools are evident.

Indeed these articles provide a deeper sense of the questions we need to be asking about how teachers might integrate new literacies into school curricula for rich learning experiences. Drawing on a range of methodologies-action research, narrative, case studies, activity theory - these papers examine issues of identity and representation, fluidities of form and function, new structures of participation for teachers and students, accrued social capital, and the role of the technologies themselves in regulating new literacy practices.

Several of the researchers examine the role of identity in new literacy practices, for teachers and students alike. As Burke reminds us, identity mediates and is mediated by various forms of textual engagement. These identities can be fluid, as when children in her study moved on and off screen as they engaged with the on-line game, "Club Penguin." Some sites are more conducive to positive identity mediation than others, as Hibbert illustrates by way of sharing her own stories and imagining an on-line site where students and teachers can bring their biographies to bear on the curriculum. We also find here poignant examples of teachers redefining their own literate and professional identities as curricular co-authors, such as articulated by Michelle in Nahachewsky's paper; or as new partners in facing the tensions of increased access to information by students, as described in the study by McClay and Peterson.

New perspectives on multimodality presented here also help us to understand how young learners are moving with fluidity between and among texts, formats, modes, and genres. The affordances of this fluidity are well documented, as well as a renewed call for innovative and supportive pedagogical practices in and out of schools. In describing how 
students re-interpreted a Shakespeare play, Hammett illustrates the skillful ways these students are using digital tools and resources - they are able to visually convey a tone in black and white, or choose a song that "suits" the play, Romeo and Juliet. Students also draw on desires, resources and texts found out of school-such as engaging with popular culture films and music. McClay and Peterson show how new text forms allow for fluidity across local and global knowledge and meaning-making among students, and Nahachewsky eloquently refers to these practices as moving toward a "palette of texts," as when students in Michelle's class engage in creating a multi-genre anti-violence film.

These studies also examine the complex effects of new literacy practices and tools on the ways students and teachers participate in activities. Hammett reflects on the intersections of play, desire, and participation among the students she worked with, while Burke illustrates how this participation can strengthen social capital and cultural leverage among affinity groups. Hibbert is moved to imagine a site that counteracts the potential harm of traditional practices and to encourage multiple ways of knowing that are simultaneously more humane, unfinished, shared, and playful. For Nachachewsky, these new practices require a new "ethos" of teaching - new values, sensibilities, norms and procedures.

But there are challenges noted as well in these new participatory structures. The work of Dagenais et al. details how a camera, as a non-human actor, can regulate participation and learning networks, shifting authority and even alienating some-as it did for one boy in a filmmaking group who was contradicted by the "director," a relationship regulated, in part, by the tool. They conclude by encouraging us to continue to explore both the affordances and constraints of new technologies, and the ways they may shift relationships among learners and their environments.

So where do we go from here? While these papers direct us to many of the key issues to contemplate, there is much more to learn about new literacies and identity, the effects of new tools and resources on learning, and changing participatory practices among students and teachers in schools. We also have a set of related questions: How are curricula becoming reshaped across the grades? How are teaching and learning practices being redefined by teachers? What are the new roles for teachers? What opportunities for new digital citizenship among students are being created or encouraged; which are lost? And perhaps most importantly, how can we as more seasoned educators get far enough ahead of the sea change to provide thoughtful responses to the many questions new teachers will ask us about how to navigate new literacies in changing, uncertain times and, as Hibbert (this volume) puts it, help them find the wisdom in practice.

\section{References}

Jenkins, H., Clinton, K., R. Purushotma, Robison, A. J., \& Weigel, M. (2006)

Confronting the challenges of participatory culture: Media education for the 21 st

Century. The MacArthur Foundation. Retrieved from

http://digitallearning.macfound.org/atf/cf/\%7B7E45C7E0-A3E0-4B89-

AC9C-E807E1B0AE4E\%7D/JENKINS_WHITE_PAPER.PDF

Sanford, K., Rogers, T., \& Kendrick, M. (Eds.). (in press). Youth literacies in new times: Everywhere everyday. Singapore: Springer. 


\section{Author Biographies}

Theresa Rogers (www.theresarogers.ca) is a professor of Language and Literacy Education at the University of British Columbia, Canada. Her interests include youth critical and multimodal literacy practices (including zining, filmmaking and theatre) and theoretical perspectives on adolescent literature. Recent related publications include Textual play, satire and counter discourses of street youth 'zining practices (2010); From Image to Ideology: Analyzing shifting identity positions of marginalized youth across the cultural sites of video production (2010), and On the Road: Examining SelfRepresentation, Youth, and Discourses of Homelessness in Young Adult Literature (2012). She has also edited books, including Reading Across Cultures (1997) and Interpretive play, Using critical perspectives to teach young adult literature (2007). An upcoming volume, co-edited with Kathy Sanford and Maureen Kendrick, is entitled Youth Literacies in New Times: Everywhere Everyday (Springer, 2013/14).

Kathy Sanford is a Professor in the Faculty of Education at the University of Victoria in British Columbia, Canada. Her research interests include gender, new literacies and technologies, learning through videogames, ePortfolios, non-formal education, and teacher education. Recent publications include Understanding the Power of New Literacies through Video Game Play and Design; Critical Literacy Learning through Video Games: Adolescent Boys' Perspectives; Complexities of Gaming Cultures: Adolescent Gamers Adapting and Transforming Learning; Videogames and Complexity Theory: Learning through Game Play; and "There's no fixed course": Rhizomatic learning communities in adolescent videogaming; as well as an edited book entitled Boys, Girls, and the Myths of Literacy and Learning. Her most recent research project is entitled Youth Civic Engagement: Real Life Learning through Virtual Games Environments. 